\title{
Predictors of the quality of life of women in peri-menopausal period
}

\author{
Katarzyna Kanadys', Anna Wiktor-Stoma², Magdalena Lewicka', Magdalena Sulima', \\ Henryk Wiktor ${ }^{1,3}$ \\ ${ }^{1}$ Department of Obstetrics, Gynaecology and Obstetrics-Gynaecological Nursing, Faculty of Health Sciences, Medical \\ University of Lublin, Poland \\ ${ }^{2}$ Department of Prosthodontics, I Medical Faculty with Dentistry Division, Medical University, Lublin, Poland \\ ${ }^{3}$ Department of Obstetrics and Gynecology, Stefan Kardynał Wyszyński District Specialist Hospital, Lublin, Poland
}

Kanadys K, Lewicka M, Wiktor-Stoma A, Sulima M, Wiktor H. Predictors of the quality of life of women in peri-menopausal period. Ann Agric Environ Med. 2016; 23(4): 641-648. doi: 10.5604/12321966.1226860

\section{Abstract}

Introduction. The peri-menopausal period is the time of many biological, psychological and social changes. The quality of life of women in this period may be conditioned by many factors, and analysis of these factors may indicate the optimum directions of prophylactic and educational actions.

Objective. Analysis of selected predictive factors of the quality of life of women in the peri-menopausal period.

Materials and method. The study covered 268 peri-menopausal women. The qualification criteria were: age 45-55, lack of mental disorders and diseases requiring hospitalization during the period of study. The study was conducted using standardized instruments: Women's Health Questionnaire - WHQ, Beck Depression Inventory (BDI) and an author-constructed questionnaire.

Results. The presented study of the quality of life showed that the women examined felt physically unattractive, lacking the full joy of life, and frequently experienced somatic complaints. Nevertheless, the respondents enjoyed life, had no constant feeling of anxiety and concern. Multi-factor analysis showed that the quality of life in the group of women in the study was affected by the following factors: level of depression, self-reported state of health, occurrence of menopausal symptoms, education level, and marital status.

Conclusions. The quality of life of the peri-menopausal women examined was the highest with respect to depressive mood (DEP) and anxiety/depressed mood (ANX), while it was the lowest with respect to the sense of attractiveness (ATT), and somatic symptoms (SOM). In addition, in the group of women in peri-menopausal period the quality of life was conditioned: level of depression, self-reported state of health, occurrence of menopausal symptoms, education level, and marital status.

\section{Key words}

peri-menopausal period, quality of life, predictors

\section{INTRODUCTION}

The peri-menopausal period is the time of physiological transition from the reproductive period towards old age. During this period there occurs cessation of endocrine ovarian function, the consequences of which are unpleasant clinical symptoms experienced by the women, called climacteric symptoms [1, 2]. To the clinical symptoms contribute unfavourable psychological and social experiences, such as: children becoming independent, illness and death of parents, deterioration of partner's state of health or his leaving or death [3]. Women in the peri-menopausal period, facing bio-psycho-social changes, require special psychoprophylactic care provided through actions biased towards the improvement of their quality of life.

The quality of life is a multi-dimensional concept, which is variously understood and defined. According to the WHO, this broad ranging concept is 'affected in a complex way by the person's physical health, psychological state, level of independence, social relationships, personal beliefs and their relationship with salient features of their environment' $[4,5,6,7,8]$.

Address for correspondence: Katarzyna Kanadys, Department of Obstetrics, Gynaecology and Obstetrics-Gynaecological Nursing, Faculty of Health Sciences, Medical University of Lublin, Poland

E-mail:kanadysk@wp.pl

Received: 25 February 2013; accepted: 15 July 2014
The quality of life of women during the peri-menopausal period is measured by questionnaires, both general and specific, i.e. specially designed for this group of women. One of the most reliable instruments is the Women's Health Questionnaire (WHQ). This questionnaire satisfies the requirements for the instrument measuring the quality of life of women aged 45-65, and additionally enables evaluation of the physical and emotional changes and wellbeing of women during the period of changes related with menopause $[9,10]$.

Due to an increase in the average life span up to 79.7 years in the countries of Western Europe, more than 1/3 of the life of a woman falls within the postmenopausal period [11]. An evaluation of the quality of life of this huge group of women may indicate optimum directions of prophylactic and educational actions.

The objective of the study was analysis of selected predictive factors of the quality of life of women in the peri-menopausal period.

\section{MATERIALS AND METHOD}

The study covered 268 peri-menopausal women who reported to outpatient departments in the city of Lublin. The criteria for qualification of women for the study were: age 45-55, and lack of mental disorders and diseases requiring hospitalization during the period of study. Women with 
iatrogenic menopause were excluded from investigations. The study was voluntary and anonymous, and consent to participate was obtained from the respondents after previous explanation of the objective and course of the study.

The research project obtained a positive opinion from the Bioethical Commission at the Medical University in Lublin (No. KE-0254/6/2008).

The study was carried out by the method of a diagnostic survey, using standardized instruments: Women's Health Questionnaire - WHQ, Beck Depression Inventory (BDI) and an author-constructed questionnaire.

Women's Health Questionnaire (WHQ). This is a specific instrument used for investigating the quality of life of women at peri-menopausal age. It enables an analysis of changes in evaluations of the state of health and general wellbeing during the period of changes related with menopause. The questionnaire consists of 37 items which allow assessment of the following 9 dimensions of health: anxiety/depressed mood (ADM, anxiety/fear (ANX), attractiveness (ATT), depressed mood (DEP), memory/concentration (MEM), menstrual symptoms (MEN), sexual behaviour (SEX), sleep problems (SLE), somatic symptoms (SOM), vasomotor symptoms (VAS), and wellbeing (WLB). The mean results for an individual dimension range from $0-1$. The lower the mean value, the better the state of health $[9,12]$.

Beck Depression Inventory (BDI). One of the instruments used for measuring depression. According to its authors, it allows assessment of the severity of depression in ill individuals, and differentiation between the healthy and those ill with depressive symptoms. In the presented study, the following criteria of intensity of depressive feeling have been adopted: 0-9 scores means no symptoms of depression, 10-16 - mild depression, 17-29 - moderate depression, and $>30$ - severe depression [13].

Statistical analysis. Performed by means of statistical software SPSS/PC. Statistical significance of the differences between two independent groups was performed using t-Student test. Also, the measure of peakedness of distribution of the data collected was investigated (kurtosis), as well as the degree of asymmetry of their distribution around the mean value (skewness). Regression analysis was applied for estimation of the size of the explained variance and identification of predictor variables, adopting the value $p>0.01$ as an exclusion criterion. The results of analysis of regression were presented by reporting the values of corrected coefficient of determination $\left(\mathrm{R}^{2}\right)$.

\section{RESULTS}

Two age groups were distinguished in the study: the first group covered 141 (52.61\%) women aged up to 50, and the second group consisted of 127 (47.39\%) respondents aged over 50 . In the population group examined, the largest number of women possessed secondary school education $55.60 \%(\mathrm{n}=149) ; 24.63 \%(\mathrm{n}=66)$ - university education, while $19.78 \%(n=53)$ had an elementary or elementary vocational education. Based on the collected data, it was found that the majority of respondents were married $(n=210 ; 78.36 \%)$, whereas every fifth woman in the study $(n=58 ; 21.64 \%)$ was single (never married, widowed, divorced). Most frequently the respondents evaluated their state of health as mediocre or poor, ( $n=153 ; 57.09 \%)$, while 115 of the women examined (42.91\%) described their state of health as good. Overall analysis of the level of depression (BDI) among the perimenopausal women in the study showed that $55.60 \%(n=149)$ of respondents had no symptoms of depression, whereas $30.97 \%(n=83)$ respondents showed mild symptoms of depression, $7.84 \%(n=21)$ - moderate, and 5.60\%, $(n=15)$ - severe depressive symptoms. The mean score of the level of depression in the group examined was $10.18 \pm 7.96$. The study showed that the majority of women participating in the study $(n=210 ; 78.36 \%)$ showed climacteric symptoms, while the remainder $21.64 \%(n=58)$ did not report such symptoms.

Figure 1 illustrates the results for the 9 dimensions of health established based on the Women's Health Questionnaire (WHQ) for women at peri-menopausal age.

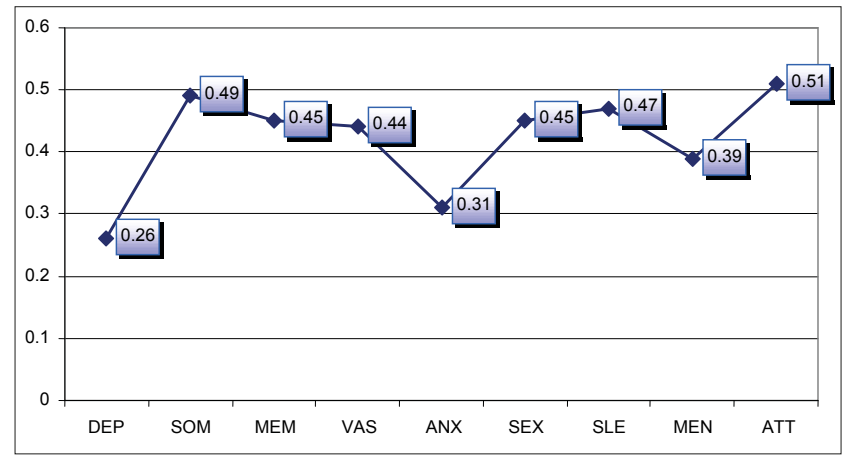

Figure 1. Dimensions of health evaluated using the WHQ questionnaire among women in peri-menopausal period

The mean evaluations of the quality of life (WHQ) were the highest (negative evaluation) in the dimension ATT (attractiveness) and in the dimension SOM (somatic symptoms), and were 0.51 and 0.49 , respectively, whereas the lowest values (positive evaluation) obtained mean values in the dimensions DEP (depressive mood) - 0.26, and ANX (anxiety/fear) - 0.31. In addition, the mean values in the dimension SLE (sleep problems) were 0.47, MEM (memory/ concentration) - 0.45, SEX (sexual behaviours) - 0.45, VAS (vasomotor symptoms) - 0.44, and MEN (menstrual symptoms) -0.39 .

The results obtained in the presented study indicated that the examined women felt physically unattractive, lacked the joys of life and did not live it to the full, and experienced various somatic complaints. However, the respondents enjoyed life, anyway, and did not experience a constant feeling of anxiety and concern.

Table 1 presents the analysis of results in individual dimensions of the quality of life WHQ, according to education level.

The presented study confirmed that education level determined the quality of life of the women examined in the following dimensions: DEP, SOM, MEM, VAS, ANX, SEX, SLE and ATT, and was higher in the group of respondents with university education, compared to those who had secondary school, elementary or elementary vocational education level. The results of own studies showed that respondents with university education enjoyed life more, had less somatic and vasomotor symptoms, also had less problems 
Table 1. Differences in individual dimensions of the quality of life (WHQ) among respondents at various education levels

\begin{tabular}{|c|c|c|c|c|c|c|c|c|}
\hline WHQ dimension & Groups compared & $\mathrm{N}$ & M & Min & Max & SD & Kurtosis & Skewness \\
\hline \multirow[t]{3}{*}{ DEP } & Elementary or elementary vocational & 53 & 0.34 & 0.00 & 1.00 & 0.27 & 0.52 & -0.42 \\
\hline & Secondary school & 149 & 0.27 & 0.00 & 1.00 & 0.24 & 0.91 & 0.52 \\
\hline & University & 66 & 0.16 & 0.00 & 0.71 & 0.21 & 1.39 & 1.02 \\
\hline \multirow[t]{3}{*}{ SOM } & Elementary or elementary vocational & 53 & 0.57 & 0.00 & 1.00 & 0.25 & -0.33 & -0.54 \\
\hline & Secondary school & 149 & 0.52 & 0.00 & 1.00 & 0.27 & 0.04 & -0.59 \\
\hline & University & 66 & 0.36 & 0.00 & 1.00 & 0.27 & 0.34 & -0.94 \\
\hline \multirow[t]{3}{*}{ MEM } & Elementary or elementary vocational & 53 & 0.48 & 0.00 & 1.00 & 0.42 & 0.12 & -1.66 \\
\hline & Secondary school & 149 & 0.49 & 0.00 & 1.00 & 0.38 & -0.03 & -1.40 \\
\hline & University & 66 & 0.33 & 0.00 & 1.00 & 0.33 & 0.51 & -1.00 \\
\hline \multirow[t]{3}{*}{ VAS } & Elementary or elementary vocational & 53 & 0.45 & 0.00 & 1.00 & 0.46 & 0.20 & -1.81 \\
\hline & Secondary school & 149 & 0.50 & 0.00 & 1.00 & 0.43 & 0.01 & -1.63 \\
\hline & University & 66 & 0.30 & 0.00 & 1.00 & 0.42 & 0.86 & -1.02 \\
\hline \multirow[t]{3}{*}{ ANX } & Elementary or elementary vocational & 53 & 0.38 & 0.00 & 1.00 & 0.34 & 0.54 & -0.81 \\
\hline & Secondary school & 149 & 0.31 & 0.00 & 1.00 & 0.27 & 0.56 & -0.48 \\
\hline & University & 66 & 0.23 & 0.00 & 1.00 & 0.28 & 0.93 & -0.03 \\
\hline \multirow[t]{3}{*}{ SEX } & Elementary or elementary vocational & 53 & 0.54 & 0.00 & 1.00 & 0.40 & -0.14 & -1.52 \\
\hline & Secondary school & 149 & 0.48 & 0.00 & 1.00 & 0.40 & 0.13 & -1.53 \\
\hline & University & 66 & 0.31 & 0.00 & 1.00 & 0.36 & 0.85 & -0.65 \\
\hline \multirow[t]{3}{*}{ SLE } & Elementary or elementary vocational & 53 & 0.53 & 0.00 & 1.00 & 0.40 & -0.12 & -1.52 \\
\hline & Secondary school & 149 & 0.49 & 0.00 & 1.00 & 0.36 & 0.02 & -1.26 \\
\hline & University & 66 & 0.37 & 0.00 & 1.00 & 0.36 & 0.44 & -1.15 \\
\hline \multirow[t]{3}{*}{ MEN } & Elementary or elementary vocational & 53 & 0.38 & 0.00 & 1.00 & 0.29 & 0.25 & -0.76 \\
\hline & Secondary school & 149 & 0.42 & 0.00 & 1.00 & 0.32 & 0.35 & -0.83 \\
\hline & University & 66 & 0.34 & 0.00 & 1.00 & 0.31 & 0.50 & -0.72 \\
\hline \multirow[t]{2}{*}{ ATT } & Elementary or elementary vocational & 53 & 0.58 & 0.00 & 1.00 & 0.37 & -0.25 & -1.13 \\
\hline & Secondary school & 149 & 0.54 & 0.00 & 1.00 & 0.39 & -0.14 & -1.30 \\
\hline \multirow[t]{3}{*}{ DEP } & Elementary or elementary vocational & school & & & & & & \\
\hline & Elementary or elementary vocational & & & & & & & \\
\hline & Secondary school - University & & & & & & & \\
\hline \multirow[t]{3}{*}{ SOM } & Elementary or elementary vocational & school & & & & & & \\
\hline & Elementary or elementary vocational & & & & & & & $04^{*}$ \\
\hline & Secondary school - University & & & & & & & \\
\hline \multirow[t]{3}{*}{ MEM } & Elementary or elementary vocational & school & & & & & & \\
\hline & Elementary or elementary vocational & & & & & & & \\
\hline & Secondary school - University & & & & & & & \\
\hline \multirow[t]{3}{*}{ VAS } & Elementary or elementary vocational & school & & & & & & \\
\hline & Elementary or elementary vocational & & & & & & & \\
\hline & Secondary school - University & & & & & & & \\
\hline \multirow[t]{3}{*}{ ANX } & Elementary or elementary vocational & school & & & & & & \\
\hline & Elementary or elementary vocational & & & & & & & \\
\hline & Secondary school - University & & & & & & & \\
\hline \multirow[t]{3}{*}{ SEX } & Elementary or elementary vocational & school & & & & & & \\
\hline & Elementary or elementary vocational & & & & & & & \\
\hline & Secondary school - University & & & & & & & \\
\hline \multirow[t]{3}{*}{ SLE } & Elementary or elementary vocational & school & & & & & & \\
\hline & Elementary or elementary vocational & & & & & & & \\
\hline & Secondary school - University & & & & & & & \\
\hline \multirow[t]{3}{*}{ MEN } & Elementary or elementary vocational & school & & & & & & \\
\hline & Elementary or elementary vocational & & & & & & & \\
\hline & Secondary school - University & & & & & & & \\
\hline ATT & Elementary or elementary vocational & school & & & & & & \\
\hline
\end{tabular}


with memory, concentration and sleep, did not experience the lack of interest in sexual life, and felt more physically attractive than those with secondary school, elementary or elementary vocational education.

Table 2 presents analysis of results of the study of the quality of life with the use of the WHQ questionnaire according to the marital status of peri-menopausal women.

Analysis of the results obtained with respect to the quality of life (WHQ) according to marital status indicated that married women obtained lower values (positive evaluation), compared to single women in all domains of the quality of life, except for attractiveness (ATT) - in this domain mean values were lower in the group of single women. Statistical analysis showed a significant difference $(p=0.03)$ in the domain ANX - which means that single women more than those married experienced anxiety and tension, and were more often concerned. In the remaining domains the differences were statistically insignificant

The study confirmed that marital status determined the quality of life only in the dimension ANX (anxiety/ fear), this quality being poorer among single than married women.

Table 2. Differences in individual dimensions of the quality of life (WHQ) according to respondents' marital status

\begin{tabular}{|c|c|c|c|c|c|c|c|c|}
\hline $\begin{array}{l}\text { WHQ } \\
\text { dimension }\end{array}$ & $\begin{array}{l}\text { Groups } \\
\text { compared }\end{array}$ & $n$ & M & Min & Max & SD & Kurtosis & Skewnes \\
\hline \multirow{2}{*}{ DEP } & Married & 210 & 0.24 & 0.00 & 1.00 & 0.23 & 0.91 & 0.20 \\
\hline & Single & 58 & 0.31 & 0.00 & 1.00 & 0.28 & 0.75 & -0.03 \\
\hline \multirow{2}{*}{ SOM } & Married & 210 & 0.47 & 0.00 & 1.00 & 0.26 & 0.05 & -0.71 \\
\hline & Single & 58 & 0.54 & 0.00 & 1.00 & 0.29 & -0.20 & -0.88 \\
\hline \multirow{2}{*}{ MEM } & Married & 210 & 0.44 & 0.00 & 1.00 & 0.37 & 0.16 & -1.36 \\
\hline & Single & 58 & 0.47 & 0.00 & 1.00 & 0.41 & 0.12 & -1.62 \\
\hline \multirow{2}{*}{ VAS } & Married & 210 & 0.44 & 0.00 & 1.00 & 0.44 & 0.25 & -1.66 \\
\hline & Single & 58 & 0.45 & 0.00 & 1.00 & 0.44 & 0.21 & -1.67 \\
\hline \multirow{2}{*}{ ANX } & Married & 210 & 0.29 & 0.00 & 1.00 & 0.28 & 0.74 & -0.28 \\
\hline & Single & 58 & 0.38 & 0.00 & 1.00 & 0.31 & 0.44 & -0.70 \\
\hline \multirow{2}{*}{ SEX } & Married & 210 & 0.43 & 0.00 & 1.00 & 0.39 & 0.32 & -1.35 \\
\hline & Single & 58 & 0.53 & 0.00 & 1.00 & 0.44 & -0.11 & -1.80 \\
\hline \multirow{2}{*}{ SLE } & Married & 210 & 0.46 & 0.00 & 1.00 & 0.37 & 0.12 & -1.32 \\
\hline & Single & 58 & 0.49 & 0.00 & 1.00 & 0.38 & 0.01 & -1.41 \\
\hline \multirow{2}{*}{ MEN } & Married & 210 & 0.39 & 0.00 & 1.00 & 0.31 & 0.32 & -0.92 \\
\hline & Single & 58 & 0.41 & 0.00 & 1.00 & 0.30 & 0.60 & -0.19 \\
\hline \multirow{2}{*}{ ATT } & Married & 210 & 0.50 & 0.00 & 1.00 & 0.37 & 0.02 & -1.17 \\
\hline & Single & 58 & 0.56 & 0.00 & 1.00 & 0.41 & -0.23 & -1.47 \\
\hline $\begin{array}{l}\text { WHQ } \\
\text { dimensions }\end{array}$ & \multicolumn{3}{|c|}{ Groups compared } & \multicolumn{3}{|l|}{$\mathrm{t}$} & \multicolumn{2}{|l|}{$\mathrm{p}$} \\
\hline DEP & \multicolumn{3}{|c|}{ Married - Single } & \multicolumn{3}{|l|}{1.91} & \multicolumn{2}{|l|}{0.06} \\
\hline SOM & \multicolumn{3}{|c|}{ Married - Single } & \multicolumn{3}{|l|}{1.66} & \multicolumn{2}{|l|}{0.10} \\
\hline MEM & \multicolumn{3}{|c|}{ Married - Single } & \multicolumn{3}{|l|}{0.55} & \multicolumn{2}{|l|}{0.58} \\
\hline VAS & \multicolumn{3}{|c|}{ Married - Single } & \multicolumn{3}{|l|}{0.17} & \multicolumn{2}{|l|}{0.87} \\
\hline ANX & \multicolumn{3}{|c|}{ Married - Single } & \multicolumn{3}{|l|}{2.19} & \multicolumn{2}{|l|}{$0.03^{*}$} \\
\hline SEX & \multicolumn{3}{|c|}{ Married - Single } & \multicolumn{3}{|l|}{1.64} & \multicolumn{2}{|l|}{0.10} \\
\hline SLE & Married - S & ngle & & 0.53 & & & 0.59 & \\
\hline MEN & Married - S & gle & & 0.42 & & & 0.68 & \\
\hline ATT & Married - S & igle & & 1.16 & & & 0.25 & \\
\hline
\end{tabular}

$\mathrm{n}$-number of respondents; $\mathrm{M}$ - arithmetic mean; Min - minimum; Max-maximum; SD-standard deviation; $\mathrm{t}$ - value of $\mathrm{t}$-Student test; $\mathrm{p}$ - level of significance.
Table 3. Differences in individual dimensions of the quality of life (WHQ) according to respondents' self-reported state of health

\begin{tabular}{|c|c|c|c|c|c|c|c|c|}
\hline $\begin{array}{l}\text { WHQ } \\
\text { dimension }\end{array}$ & $\begin{array}{l}\text { Groups } \\
\text { compared }\end{array}$ & $\mathrm{n}$ & M & Min & Max & SD & Kurtosis & $\begin{array}{c}\text { Skew- } \\
\text { ness }\end{array}$ \\
\hline \multirow[b]{2}{*}{ DEP } & Good & 115 & 0.16 & 0.00 & 0.71 & 0.19 & 0.99 & -0.00 \\
\hline & $\begin{array}{l}\text { Mediocre } \\
\text { or poor }\end{array}$ & 153 & 0.33 & 0.00 & 1.00 & 0.26 & 0.69 & -0.19 \\
\hline \multirow[b]{2}{*}{ SOM } & Good & 115 & 0.35 & 0.00 & 1.00 & 0.25 & 0.46 & -0.30 \\
\hline & $\begin{array}{l}\text { Mediocre } \\
\text { or poor }\end{array}$ & 153 & 0.59 & 0.00 & 1.00 & 0.24 & -0.19 & -0.57 \\
\hline \multirow[b]{2}{*}{ MEM } & Good & 115 & 0.29 & 0.00 & 1.00 & 0.34 & 0.80 & -0.67 \\
\hline & $\begin{array}{l}\text { Mediocre } \\
\text { or poor }\end{array}$ & 153 & 0.57 & 0.00 & 1.00 & 0.37 & -0.29 & -1.23 \\
\hline \multirow[b]{2}{*}{ VAS } & Good & 115 & 0.29 & 0.00 & 1.00 & 0.37 & 0.83 & -0.69 \\
\hline & $\begin{array}{l}\text { Mediocre } \\
\text { or poor }\end{array}$ & 153 & 0.55 & 0.00 & 1.00 & 0.45 & -0.20 & -1.76 \\
\hline \multirow[b]{2}{*}{ ANX } & Good & 115 & 0.18 & 0.00 & 1.00 & 0.23 & 1.18 & 0.72 \\
\hline & $\begin{array}{l}\text { Mediocre } \\
\text { or poor }\end{array}$ & 153 & 0.40 & 0.00 & 1.00 & 0.30 & 0.37 & -0.64 \\
\hline \multirow[b]{2}{*}{ SEX } & Good & 115 & 0.32 & 0.00 & 1.00 & 0.36 & 0.72 & -0.89 \\
\hline & $\begin{array}{l}\text { Mediocre } \\
\text { or poor }\end{array}$ & 153 & 0.55 & 0.00 & 1.00 & 0.40 & -0.11 & -1.53 \\
\hline \multirow[b]{2}{*}{ SLE } & Good & 115 & 0.32 & 0.00 & 1.00 & 0.33 & 0.57 & -0.89 \\
\hline & $\begin{array}{l}\text { Mediocre } \\
\text { or poor }\end{array}$ & 153 & 0.58 & 0.00 & 1.00 & 0.36 & -0.28 & -1.22 \\
\hline \multirow[b]{2}{*}{ MEN } & Good & 115 & 0.33 & 0.00 & 1.00 & 0.30 & 0.60 & -0.59 \\
\hline & $\begin{array}{l}\text { Mediocre } \\
\text { or poor }\end{array}$ & 153 & 0.44 & 0.00 & 1.00 & 0.31 & 0.23 & -0.80 \\
\hline \multirow[b]{2}{*}{$A \|$} & Good & 115 & 0.41 & 0.00 & 1.00 & 0.36 & 0.27 & -1.01 \\
\hline & $\begin{array}{l}\text { Mediocre } \\
\text { or poor }\end{array}$ & 153 & 0.58 & 0.00 & 1.00 & 0.38 & -0.29 & -1.22 \\
\hline
\end{tabular}

\begin{tabular}{llll}
\hline $\begin{array}{l}\text { WHQ } \\
\text { dimensions }\end{array}$ & Groups compared & $\mathrm{t}$ & $\mathrm{p}$ \\
\hline DEP & Good-Mediocre or poor & -5.96 & $0.000001^{*}$ \\
\hline SOM & Good-Mediocre or poor & -7.99 & $0.000001^{*}$ \\
\hline MEM & Good-Mediocre or poor & -6.26 & $0.000001^{*}$ \\
\hline VAS & Good-Mediocre or poor & -4.92 & $0.000001^{*}$ \\
\hline ANX & Good-Mediocre or poor & -6.65 & $0.000001^{*}$ \\
\hline SEX & Good-Mediocre or poor & -4.86 & $0.000002^{*}$ \\
\hline SLE & Good-Mediocre or poor & -5.86 & $0.000001^{*}$ \\
\hline MEN & Good-Mediocre or poor & -2.83 & $0.005^{*}$ \\
\hline ATT & Good-Mediocre or poor & -3.70 & $0.0003^{*}$
\end{tabular}

$\mathrm{n}$-number of respondents; $\mathrm{M}$ - arithmetic mean; Min - minimum; Max-maximum; SD-standard deviation; $\mathrm{t}$ - value of $\mathrm{t}$-Student test; $\mathrm{p}$ - level of significance

Table 3 presents the results of the study of the quality of life using the WHQ questionnaire according to the self-reported state of health among peri-menopausal women in the study.

The study showed that self-reported state of health determined the quality of life in all nine domains of health, and this quality was better in the group of respondents who evaluated their health status as good, compared to those who described it as poor or mediocre.

Table 4 presents the analysis of results in individual dimensions of the respondents' quality of life WHQ, according to the occurrence of menopausal symptoms.

Based on the results of the study, it was observed that the occurrence of menopausal symptoms determined the respondents' quality of life in the following dimensions: 
Table 4. Differences in individual dimensions of the quality of life (WHQ) according to occurrence of menopausal

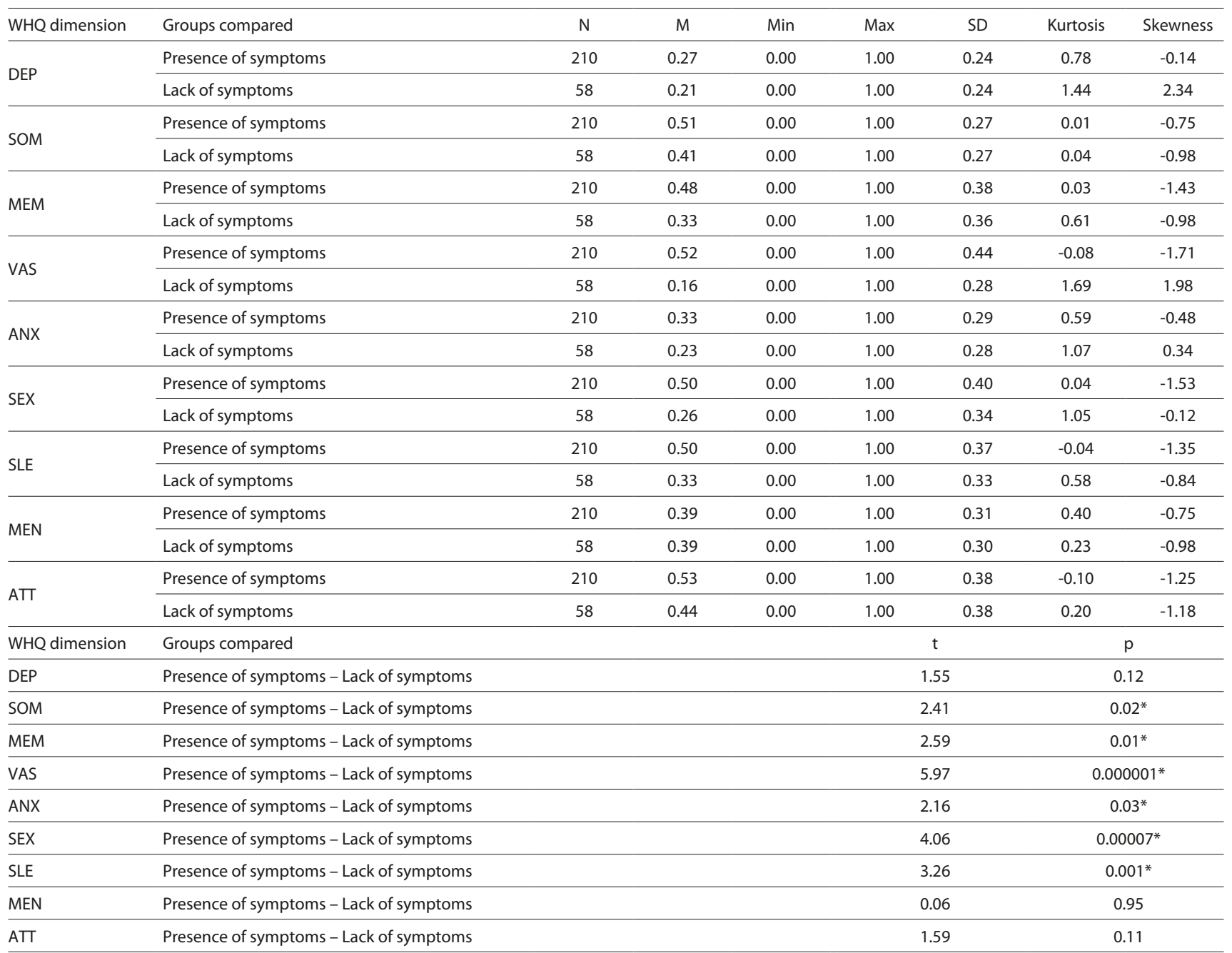

$\mathrm{n}$ - number of respondents; $\mathrm{M}$ - arithmetic mean; Min - minimum; Max - maximum; SD - standard deviation; $\mathrm{t}$ - value of $\mathrm{t}$-Student test; $\mathrm{p}$ - level of significance.

(SOM), (MEM), (VAS), (ANX), (SEX) and (SLE), and was lower in the group of women who suffered menopausal symptoms, compared to those who did not experience such symptoms.

Table 5 presents multiple regression analysis of the variable of quality of life (WHQ), with consideration of selected factors during the peri-menopausal period.

Regression analysis was applied in order to evaluate the size of explained variance and identify predictors of the variable WHQ, adopting as the exclusion criterion for $\mathrm{F} p>0.01$. For the assessment of predictive variables for WHQ, evaluation of their significance, and estimation of the size of variance

Table 5. Multiple regression analysis on the variable WHQ.

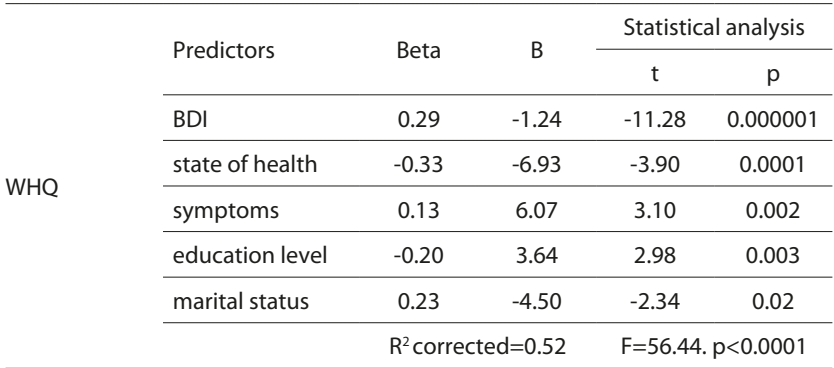

B - Beta coefficient; Beta - Beta Index; R2 - value of coefficient of determinant; F - value of $F$ ratio for the ANOVA Table; $\mathrm{t}$ - value of $\mathrm{t}$-Student test; $\mathrm{p}$ - level of significance explained by these factors, stepwise regression analysis was used. Each time, the following variables were introduced into the regression model: age, education level, state of health, menopausal symptoms, treatment, and level of depression (Beck Depression Inventory).

Multiple regression analysis confirmed that variables of the BDI, state of health, occurrence of menopausal symptoms, education level, and marital status, explained as much as 52\% of variance of the variable WHQ, which means that $48 \%$ of variance is explained by other factors not considered in the presented study.

The values calculated allow transcription of the regression in the following form:

$\mathrm{WHQ}=-1.24 \cdot \mathrm{BDI}-6.93 \cdot$ state of health $+6.07 \cdot$ symptoms + 3.64-education level $-4.50 \cdot$ marital status \pm 12.92 .

The coefficient B for BDI was -1.24, which means that if the value of this variable decreased by one unit it is expected that WHQ will increase by 1.24 units. Similarly, coefficient B for the state of health was 6.93, and an increase in the evaluation of health status resulted in an increase in the quality of life (WHQ) by 6.93 units. Also, the occurrence of menopausal symptoms was accompanied by an increase in WHQ by 6.07 units. In single women, it was observed that the quality of life (WHQ) decreased by 4.50 units. 
The study confirmed that the following factors exerted an effect on the quality of life (WHQ) in the group of women examined: severity of depression, self-reported state of health, occurrence of menopausal symptoms, education level, and marital status.

\section{DISCUSSION}

The peri-menopausal period is the time of physiological transition from the reproductive period towards old age, and is the time of many biological, psychological and social changes. The quality of life of women in this period may be conditioned by many predictive factors. Analysis of these factors may indicate the optimum directions of prophylactic and educational actions in the group of women at perimenopausal age.

The presented study of the quality of life conducted using the Women's Health Questionnaire (WHQ) showed that the respondents enjoyed life, anyway, and did not experience a constant feeling of anxiety and concern. In addition, the women in the study felt physically unattractive, were lacking the sense of life and living it to the full, and experienced frequent somatic complaints, e.g. headaches or back pain. The results of own study are in accordance with the results obtained by Bińkowska [12], who found that women aged 45 - 54 enjoy life, feel physically unattractive, and experience discomfort due to various pain complaints.

The presented study carried out with the use of the WHQ questionnaire showed that education level conditioned the quality of life of the examined women in the dimensions: DEP, SOM, MEM, VAS, ANX, SEX, SLE and ATT, this quality being higher among women possessing university education, compared to those with secondary school, elementary or elementary vocational education level. The results of own study are consistent with the results obtained by Binkowska [12], who observed that therespondents with elementary/ elementary vocational education had lower characteristics of the quality of life in the dimension DEP - depressive moods, ANX - anxiety/fear, and SLE - sleep problems, compared to respondents possessing university or secondary school education. Similar observations were made by Pacian et al. [14], who in their studies carried out in a group of women aged 45-65 with breast cancer, confirmed a significant relationship between the quality of life and higher education level. Better quality of life of women with a higher education level was also noted in the studies by Karaçam and Şeker [15], and Koundi et al. [16] and Zagozdzon et al. [7]. In addition, Avis et al. [17] in their studies in a population group of 13,874 women aged 40-55, conducted among five nationalities in the USA, found a relationship between education level and quality of life.

Nevertheless, the above-quoted researchers indicated that cultural factors may condition the relationship between the respondents' education level and their quality of life. In own studies, it was observed that women with a higher level of education were characterized by a better quality of life.

In the group of women covered by the presented study, analysis of the quality of life (WHQ) according to marital status confirmed that married women had a better quality of life than those who were single, in all domains of the quality of life. However, statistical analysis showed a significant difference $(p=0.03)$ only with respect to the domain
ANX - which means that single women, more often than married women experienced anxiety, tension, and were more frequently concerned. In the remaining domains, the differences were statistically insignificant. The presented study is consistent with investigations by Koundi et al. [16], who found that marital status significantly conditions the quality of life of women at peri-menopausal age.

The above-mentioned researchers emphasized that single and childless women had a lower quality of life and higher anxiety, compared to married women. Also, Giannoulia et al. [8] in studies conducted in a group of 1,140 Greek women aged 45-, showed that married women with a good material standard had a significantly higher quality of life than widows and divorced women who had a lower income. Moreover, Avis et al. [17], and Li et al. [18] reported that married women who had children maintained a better general state of health and better quality of life.

The group of women in the current study aged 45-55 were characterized by specific health problems, which may have depended on many factors, e.g. stage of menopausal period, and occurrence of climacteric symptoms. The presented study confirmed that the state of health determines the quality of life in all nine dimensions of health evaluated using the WHQ questionnaire. The quality of life was better in the group of respondents who reported their state of health as good, compared to the group of women who evaluated their health status as poor or mediocre. The results of own study are in accordance with the results of studies by Avis et al. [17], which covered 13,874 women aged $40-55$. These researchers showed that women who had a poor health status also had a lower quality of life. Similar observations were made by Lai et al. [19] and Żołnierczuk-Kieliszek et al. [20] in their studies carried out in a group of women with a poor state of health, whose quality of life was lower than in the control group of women who had a good health status. However, in Chmaj-Wierzchowska's [21] study conducted among aroup of women with urinary incontinence, it was highlighted that this disease significantly influences the quality of life of women in the peri-menopausal period. In addition, Chen et al. [22] evaluated the effect of factors determining the quality of life of Chinese women aged 35-64, and showed that self-reported state of health is an important predictor of the quality of life of women.

In the literature to-date, an attempt has already been undertaken to establish a possible relationship between the occurrence of menopausal symptoms and the quality of life of women at menopausal age. Utian [23] reported that vasomotor symptoms may exert a significant effect on the quality of life of women, resulting in the deterioration of their physical condition, decrease in productivity at work, as well as contributing to disorders in social relations. In the opinions of experts who met in Pisa in 2006 (International Menopause Society Expert Workshop), a reduced level of hormones during the peri-menopausal period exerts a tremendous effect on the functioning of the entire body, and causes symptoms which considerably affect the quality of life and sexuality of women [24].

The above-mentioned researchers indicated the need for keeping records of the occurring climacteric symptoms, and implementation of an adequate medical procedure, because menopausal symptoms, which decrease the quality of life, should be considered as a sign of individual, biological susceptibility to the development of diseases typical of 
the peri-menopausal age [24]. In addition, many studies confirmed that climacteric symptoms have a negative effect on the quality of life of the women examined $[2,8,15,25$, $26,27,28]$. Also, Genazzani et al. [29] in their studies carried out in seven European countries: France, Belgium, Germany, Holland, Spain, Switzerland, and the United Kingdom, in a group of 4,201 women at peri-menopausal age, observed that in $94 \%$ of women there occurred climacteric symptoms, which in nearly a half of the respondents negatively affected their daily functioning. The studies by Lai et al. [19] did not confirm the climacteric symptoms on the quality of life of women at peri-menopausal age, apart from sleep problems and emotional disorders; the latter had a negative effect on the patients' wellbeing. In turn, Satoh and Ohashi [30] conducted studies among healthy Japanese women aged 45-55, in order to analyze the correlation between the quality of life and intensification of menopausal symptoms. The above-quoted researchers noted that women who suffered menopausal symptoms had a poorer quality of life with respect to all the domains specified with the use of the WHOQOL instrument.

In the group of women in the presented study, it was found that the occurrence of menopausal symptoms determined the quality of life of these women in the following dimensions: (SOM), (MEM), (VAS), (ANX), (SEX) and (SLE). The results of own studies confirmed that the occurrence of menopausal symptoms contributed to the deterioration of the quality of life of the women in the study.

In the relevant literature there are many reports suggesting an increased risk of the occurrence of depression among peri-menopausal women, especially those with intensified vasomotor symptoms $[3,31,32,33]$. The results of own studies are consistent with the opinions by the above-mentioned researchers, because in the group of women covered by the presented study the occurrence of menopausal symptoms determined the level of depression, which was significantly higher among the respondents who experienced menopausal symptoms, compared to the women in whom such symptoms did not occur.

Multi-factor analysis of the results obtained in own studies showed that factors such as: severity of depression (BDI), state of health, occurrence of menopausal symptoms, education level, and marital status conditioned as much as $52 \%$ of the quality of life determined with the use of the WHQ questionnaire, which means that $48 \%$ of the quality of life was conditioned by other factors, which have not been considered in the presented study.

Summing up, it should be presumed that the presented study confirms that a lower education level, single marital status, poor state of health, depression, and the occurrence of menopausal symptoms contribute to the deterioration of the quality of life during the

peri-menopausal period. Thus, the results of own studies obtained indicate that there is a need for undertaking diagnostic-therapeutic and prophylactic-educational actions in the group of women with lower education level, who are single, evaluate their state of health as poor, and complain of menopausal symptoms. These actions may contribute to the improvement in the quality of life of women during the peri-menopausal period.

\section{CONCLUSIONS}

1. The quality of life among the peri-menopausal women examined was the highest with respect to depression moods (DEP), and anxiety/fear (ANX), while the lowest life quality was observed with respect to the sense of attractiveness (ATT), and somatic symptoms (SOM),

2. In the group of peri-menopausal women in the study the quality of life was determined by: severity of depression, self-reported state of health, occurrence of menopausal symptoms, education level, and marital status.

\section{REFERENCES}

1. Bielawska-Batorowicz E. Występowanie objawów uznawanych za typowe dla menopauzy u kobiet i mężczyzn w wieku 45-55 lat. (Occurrence of symptoms considered as typical of menopause among males and females aged 45-55) Prz Menopauzalny 2005; 1: 53-60 (in Polish).

2. Elsabagh EEM, Allah ESA. Menopausal symptoms and the quality of life among pre/post menopausal women from rural area in Zagazig city. Life Sci J. 2012; 9 (2): 283-291.

3. Humeniuk E, Bojar I, Owoc A, Wojtyła A, Fronczak A. Psychosocial conditioning of depressive disorders in post-menopausal women. Ann Agric Environ Med. 2011; 18(2): 441-445.

4. The Whoqol Group. The world health organization quality of life assessment (Whoqol). Position paper from the world organization. Position paper from the world health organization. Soc Sci Med. 1995; 41(10): 1403-1409.

5. Daszkowska J. Jakość życia w koncepcjach związanych ze zdrowiem. (Quality of life in health-related concepts). Prz Med Uniw Rzesz. 2006; 2: 122-128 (in Polish).

6. Kanadys K, Lewicka M, Wiktor K, Bąk M, Wiktor H. The quality of life women in perimenopausal period - the explanation of the notions measurement metods. In: Fidecki W, Wysokiński M, (ed.). Select problems of the ageing population. Szk Wyższ, Radom 2009: 231-238.

7. Zagozdzon P, Kolarzyk E, Marcinkowski JT. Quality of life and rural place of residence in Polish women - population based study. Ann Agric Environ Med. 2011; 18(2); 429-432.

8. Giannoulia P, Zervasb I, Armenia E, et al. Determinants of quality of life in Greek middle-age women: A population survey. Maturitas 2012; 71: $154-161$.

9. Girod I, Abetz L, de la Loge C. Women's Health Questionnaire - User Manual. MAPI Research Institute 2004: 3-56.

10. Shin H, Shin HS. Measurement of quality of life in menopausal women: a systematic review. West. J Nursing Res. 2012; 34 (4): 475-503.

11. Drews K, Seremak-Mrozikiewicz A, Pieńkowski W. Ginekologia geriatryczna. (Geriatric gynaecology) In: Słomko Z, (ed.). Ginekologia. Warszawa: PZWL; 2008: 431-449.

12. Bińkowska M. Badanie postaw i zachowań zdrowotnych oraz jakości życia reprezentatywnej grupy kobiet polskich w wieku od 45 do 54 lat. (Studies of attitudes and health behaviours and the quality of life of a group of Polish women aged 45-54) Prz Menopauzalny 2005, supl.; 1: 4-64 (in Polish).

13. Beck AT, Steer RA. Beck Inventory Mannual. The Psychological Corporation 1993, Harcourt Brace \& Co,

14. Pacian A, Kulik TB, Pacian J, Chruściel P, Żołnierczuk-Kieliszek D, Jarosz M. Psychosocial aspect of quality of life of Polish women with Brest cancer. Ann Agric Environ Med. 2012; 19(3): 509-512.

15. Karaçam Z, Şeker SE. Factors associated with menopausal symptoms and their relationship with the quality of life among Turkish women. Maturitas 2007; 58: 75-82.

16. Koundi KL, Christodoulakos GE, Lambrinoudaki IV, Zervas IM, Spyropoulou A, Fexi P. Quality of life and psychological symptoms in Greek postmenopausal women: Association with hormone therapy. Gynecol Endocrinol. 2006; 22(12): 660-668.

17. Avis NE, Assmann SF, Kravitz HM, Ganz PA, Ory M. Quality of life in diverse groups of midlife women: Assessing the influence of menopause, health status and psychosocial and demographic factors. Qual Life Res. 2004; 13: 933-946.

18. Li C, Borgfeldt C, Samsioe G, Lidfeldt J, Nerbrand C. Background factors influencing somatic and psychological symptoms in middle- 
age women with different hormonal status: a population-based study of Swedish women. Maturitas 2005; 52: 306-318.

19. Lai JN, Chen HJ, Chen CM, Chen PC, Wang JD. Quality of life and climacteric complaints amongst women seeking medical advice in Taiwan: assessment using the WHOQOL-BREF questionnaire. Climacteric 2006; 9: 119-128.

20. Żołnierczuk-Kieliszek D, Kulik TB, Pacian A. Predictors of quality of life in peri- and postmenopausal Polish women living in Lublin Voivodeship. Climacteric 2011; 14; (6): 669-676.

21. Chmaj-Wierzchowska K, Pięta B, Kotecka M, Michalak M, Sajdak S, Opala T. Three most important etiological factors of occurrence of stress urinary incontinence in nulliparous pre-and postmenopausal Polish women. Ann Agric Environ Med 2012; 19(3): 581-585.

22. Chen Y, Lin S-Q, Wei Y, Gao HL, Wu ZL. Menopause-specific quality of life satisfaction in community-dwelling menopausal women in China. Gynecol Endocrinol. 2007; 23 (3): 166-172.

23. Utian WH. Psychosocial and socioeconomic burden of vasomotor symptoms in menopause: A comprehensive review. Health Qual. Life Outcomes. 2005; 3: 47.

24. Genazzani AR, Gambacciani M, Simoncini T. Menopause and aging, quality of life and sexuality. International Menopause Society Expert Workshop. Climacteric 2007; 10: 88-96.

25. Ayers B, Hunter MS. Health-related quality of life of women with menopausal hot flushes and night sweats. Climacteric 2013; 16: 235-239.
26. Özkan S, Alatas SE, Zencir M. Women,s quality of life in the premenopausal and postmenopausal periods. Qual Life Res. 2005; 14: 1795-1801.

27. Conde DM, Pinto-Neto AM, Santos-Sá D, Costa-Paiva L, Martinez EZ. Factors associated with quality of life in a cohort of postmenopausal women. Gynecol Endocrinol. 2006; 22(8): 441-446.

28. Waidyasekera H, Wijewardena K, Lindmark G, Naeseen T. Menopausal symptoms and quality of life during the menopausal transition in Sri Lankan women. Menopause 2009; 16(1): 164-170.

29. Genazzani AR, Schneider HPG, Nijland E. The European Menopause Survey 2005: What do women think right now about menopause and HRT? Climacteric 2005; 8 suppl. 2: 96.

30. Satoh T, Ohashi K. Quality-of-life assessment in community-dwelling, middle-aged, healthy women in Japan. Climacteric 2005; 8: 145-153.

31. Bromberger JT, Kravitz HM. Mood and menopause: findings from the Study of Women's Health Across the Nation (SWAN) over 10 years. Obstet Gynecol Clin North Am. 2011; 38(3): 609-625.

32. Soares CN. Can depression be a menopause-associated risk? BMC Med. 2010; 1; 8:79.

33. Gibbs Z, Lee S, Kulkarni J. What factors determine whether a woman becomes depressed during the perimenopause? Arch Women's Ment Health. 2012; 15(5): 323-332. 